M. S. PLESHKO 1,2, Professor, Doctor of Engineering Sciences, mixail-stepan@mail.ru A. N. PANKRATENKO ${ }^{1}$, Head of Department, Professor, Doctor of Engineering Sciences M. V. PLESHKO ${ }^{1}$, Associate Professor, Candidate of Engineering Sciences A. A. NASONOV ${ }^{3}$, Associate Professor, Candidate of Engineering Sciences

${ }^{1}$ National University of Science and Technology-MISIS, Moscow, Russia

${ }^{2}$ Don State Technical University, Rostov-on-Don, Russia

${ }^{3}$ Platov South-Russian State Polytechnic University (NPI), Novocherkassk, Russia

\title{
ASSESSMENT OF STRESS-STRAIN BEHAVIOR OF SHAFT LINING IN BOTTOMHOLE AREA DURING SINKING BY REAL-TIME MONITORING AND COMPUTER MODELING DATA
}

\section{Introduction}

The general trend in the extractive industry in the modern world is the growing depths of mineral mining. The open pit mines need to transfer to the underground method in order to access promising resources of deep and super deep deposits.

Deep deposits are accessed by sinking of new shafts or via deepening of the existing vertical shafts. Shaft construction is one of the most complex, time-consuming and expensive stages in the general cycle of commissioning a mine. This is confirmed by the data of major mining projects in the 21st century in Russia: JSC Gai MPP; Aikhal, Mir and Udachny mines; UK ALROSA CJSC; Gremyachinsk mine of EuroChem-VolgaKali; Palashersky and Upper Kama potash deposits; Skalisty mine of Norilsk Nickel, and others [1-3].

All deposits are accessed via vertical shafts from 860 to $2054 \mathrm{~m}$ deep. The experience gained in the shaft construction showed that the geomechanical processes and various phenomena induced by confining pressure at the great depths intensified, and the stability of the openings reduced, which led to the reduction in the construction rates, increases costs, higher risk of mining, as well as to enhanced environmental impact. In many deep shafts during sinking, hazardous and emergency situations arose due to the loss of stability of the openings, falls and excessive deformation of rocks, ground subsidence, flooding of the shafts, shows of gas and oil, damage of the lining and reinforcement. The average speed of shaft construction was lower than $20 \mathrm{~m} /$ month, and the construction duration reached 7 years. Such situation is typical for all regions of the world with the developed mining industry, and the negative consequences become a critical obstacle for the advance in the industry [4-8].

To increase the efficiency and safety of shaft construction, an integrated assessment of the stress-strain behavior and safety factor of shaft lining is required. The assessment should be complete and timely, and the made technical and technological decision should be consistent with the geological conditions and, if necessary, be adjustable with regard to new incoming data. This approach, in particular, is included in the
With an increase in the depth of shafting and subsequent risk growth, it becomes necessary to make a maximum accurate estimate of the actual stress-strain behavior of the shaft lining. Real-time monitoring and numerical simulation of the bottomhole zone of a shaft in tensometric sensors glued along the rock bolts. As a result of the research, an array of data on afferent sizes of its grouting in the borehole. In all experimental sites, the mini(the $3 D$ finite element models were built for the bottomhole area tion nonlinearity by using stepwise iterative procedures. The comparison of the experimental and numerical simulation results shows the similar qualitative distribution of forces along the rock bolts. According to the quantitative analysis, the maximum deviation of the force values never exceeds $19 \%$. The higher calculated values can be explained by the fact that numerical modeling neglects structural yielding of the rock bolts. The obtained comparative data concorrectness of the numerical models. Based on that, the numerical models were then As the main method for increasing the bearing capacity of the lining, it is recommended to use

Keywords: vertical shaft, lining, rock bolt, concrete, stress-strain behavior, monitornumerical simulation.

DOI: 10.17580/em.2021.01.05 well-known NATM (New Austrian Tunneling Method), which includes geotechnical monitoring in the bottomhole area.

Since the early 1990s the investigation of underground excavations and adjacent rock mass, as well as their qualitative and quantitative stress-strain analysis widely use integrated automated monitoring systems with dedicated software packages and computer equipment. In consequence of this approach, the completeness and accuracy of the received data was improved, the speed of data processing was increased, and the computational and analytical methods based on solving inverse geomechanical problems were evolved [9-11].

On the other hand, standard geotechnical monitoring in vertical shafts remains a complex and expensive process, and also decelerates construction of shafts. Monitoring is often sampling, and the data completeness and accuracy worsen 


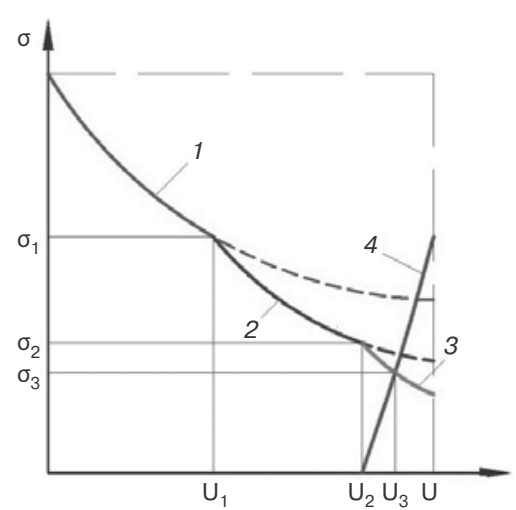

Fig. 1. Determination of liningrock mass system equilibrium by deformation curves of the system components:

1 - exposed rock mass; 2 - rock mass with temporary support; 3 - rock mass with temporary support and permanent lining; 4 - permanent lining
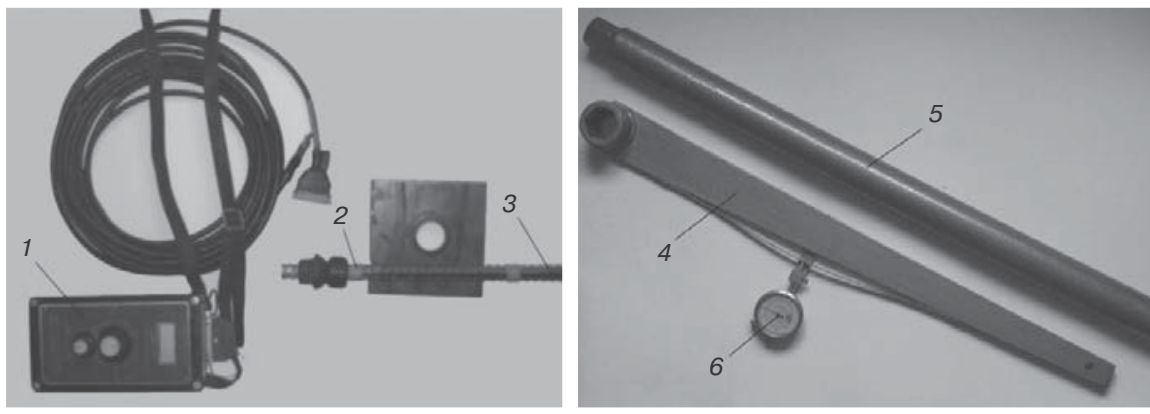

Fig. 2.Tools for controlling tensile forces in rock bolts:

1 - ISSM device; 2 - strain gage sensor; 3 - strain gauged rock bolt; 4 - torque wrench; 5 adapter; 6 - dial travel indicator

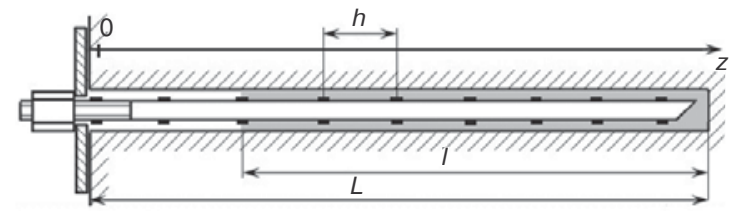

Fig. 3. Rock bolt design:

$L-$ length of the working part of the rock bolt; $I$ - length of rock bolt grouting in the borehole; $h$ distance between strain gauges with increasing depth of sinking. In this connection, it is very important to develop methods for real-time monitoring of deep shafts, as well as to create opportunities for prompt adjustment of the pre-made design decisions based on the received information. This paper focuses on this problem solution.

\section{Material and methods}

When in the Russian market, the large international shaft contracting companies (Thyssen Schachtbau, Shaft Sinkers PTY Limited) brought the technology of concurrent lining while sinking. The bottomhole area is reinforced with rock bolts and shotcrete (temporary support).

In the process of shaft construction according to this scheme, we can distinguish three main stages of rock deformation in the bottomhole area of the shaft (Fig. 1):

- Rock deformation after exposure until installation and actuation of temporary support; this stage is characterized by the horizontal displacement $U_{1}$ with a gradual decrease in the horizontal shear stresses $\sigma_{1}$.

- Rock deformation together with the temporary support before installation of the permanent structure (displacement $\mathrm{U}_{2}$, stress $\sigma_{2}$ ).

- Rock deformation after the permanent lining installation and actuation until the static equilibrium in the lining-rock mass system (displacement $U_{3}$, stress $\sigma_{3}$ ).

The total displacements $U_{1}, U_{2}$ and $U_{3}$ govern the stressstrain parameters in the lining-rock mass system after setting of static equilibrium. The first stage of deformation takes place during cleanout and further sinking. In the second stage, as a result of rock bolting (temporary support) the rock exposed is enveloped with an annular layer with increased deformation and strength characteristics as against the rocks have, which leads to a more intense reduction of stresses. The third stage of deformation, reflective of actuation of permanent lining, is relatively short, which makes it impossible to adjust its parameters. Thus, the most effective monitoring of the bottomhole area in the shaft can be implemented at the second stage of deformation.

In order to simplify monitoring, as well as reduce the time and material costs, was propose a method, according to which one of the parameters of the stress-strain behavior of the lining-rock mass system is measured, while the rest parameters are estimated on the basis of computer modeling by analytical or numerical methods. This approach opens up wide opportunities for implementing the principles of BIM modeling (Building Information Model), which is the creation of a full information model of the bottomhole area of a vertical shaft. As the controlled parameter, the tensile force in the rock bolts of the temporary support is assumed, which is a function of the intensity of the displacements $U_{2}$.

The proposed method was tested in the vertical shafts of Krasnoarmeiskaya-Zapadnaya mine in Donbass, in three experimental sites in similar geological conditions.

The characteristics of the test sites are presented in Table 1.

Reinforced concrete and rock bolting of the borehole bottom was performed to ensure rock stability in all three sites. The rock bolting density was $1 \mathrm{bolt} / \mathrm{m}^{2}$. As a basic design, a standard cemented rock bolt composed of a steel bar A400C, a base plate, a bolt washer and a locknut was adopted. At the outer end, the bolt is cut at an angle of $450 \mathrm{deg}$, on the inner end it has a thread. The parameters of the rock bolts were determined by preliminary calculation: length of $1.8 \mathrm{~m}$, diameter of $22 \mathrm{~mm}$. The main technical characteristics of the rock bolts are given in Table 2 .

The tensile forces in the rock bolts were determined by the ISSM (Intrinsically Safe Strain Meter, Model 1041, Soil Instruments Limited, UK). The measurement error is $2 \%$ (Fig. 2).

\section{Table 1. Characteristics of test sites}

\begin{tabular}{|c|c|c|c|c|}
\hline $\begin{array}{c}\text { Site } \\
\text { No. }\end{array}$ & Shaft & $\begin{array}{c}\text { Design bore } \\
\text { diameter, } \mathrm{m}\end{array}$ & $\begin{array}{c}\text { Rough design } \\
\text { diameter, } \mathrm{m}\end{array}$ & Site limits, $\mathrm{m}$ \\
\hline 1 & $\begin{array}{c}\text { Service shaft } \\
\text { No. 2 }\end{array}$ & 8.0 & 9.0 & $229.8-238.0$ \\
\hline 2 & $\begin{array}{c}\text { Skip shaft } \\
\text { No. 2 }\end{array}$ & 7.0 & 8.0 & $473.9-481.8$ \\
\hline 3 & $\begin{array}{c}\text { Skip shaft } \\
\text { No. 2 }\end{array}$ & 7.0 & 8.0 & $243.5-252.8$ \\
\hline
\end{tabular}


Table 2. Technical details of rock bolts

\begin{tabular}{|l|c|}
\hline \multicolumn{1}{|c|}{ Main technical details } & Value \\
\hline Thread: & $\mathrm{M} 24$ \\
size & 20.3 \\
minimum diameter, mm & 3.0 \\
pitch, mm & $150 \pm 1$ \\
length, mm & \\
\hline Load bearing capacity in rocks with & \\
a strength more than 30 MPa at the \\
concrete reinforcement length more \\
than 1.0 m, kN, not less than
\end{tabular}
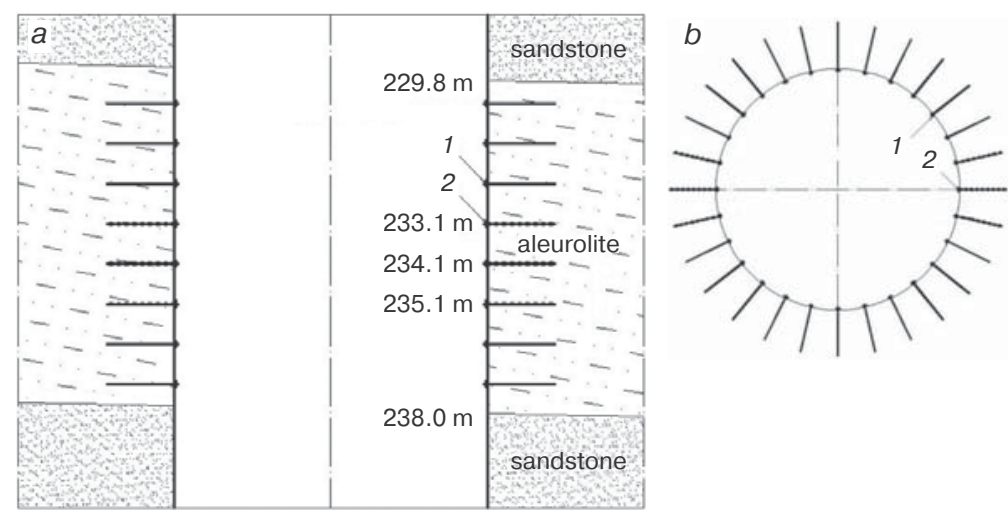

Fig. 4. Elevation view (a) and cross-section (b) of experimental site No. 1: 1 - regular rock bolt; 2 - strain gauged rock bolt
When installing temporary support at the borehole bottom, along with conventional rock bolts, were use the rock bolts with pre-glued strain gage sensors 2STRDMT (Soil Instruments Limited, UK). The structure of the rock bolt is shown in Fig. $\mathbf{3}$. The strain gauges were installed with a pitch $\mathrm{h}=200 \mathrm{~mm}$ along the rock bolts.

Pre-tensioning of the rock bolts was leveled to $30 \mathrm{kN}$ using a torque wrench with a dial travel indicator 8 hours after their installation (Fig. 3). The tensile forces in the rock bolts were determined before installation of the permanent lining from the sinking platform at a distance of about $25 \mathrm{~m}$ from the bottomhole.

To analyze the distribution of forces, 18 strain gauged rock bolts with different length of grouting in the borehole were installed at each site. In these settings, 6 rock bolts were fully grouted, 6 anchors had grouting length of $1.4 \mathrm{~m}$; the rest rock bolts had the grouting length $I=1.0 \mathrm{~m}$.

The elevation view and the cross-section of the first experimental site are shown in Fig. 4. The remaining experimental site had the similar structure and layout of rock bolting.

During the research, the following parameters and characteristics were also monitored:

- Altitude of horizontal section of the shaft in the measurement area;

- Length of rock bolt hole;

- Characteristic of bottomhole area rocks;

- Water cut in the measuring site.

As a result of the study, a large amount of data on 486 values of tensile forces in the rock bolts before the permanent lining installation was obtained.

\section{Numerical modeling}

The computer modeling is carried out using Lira-9.0 program complex, which implements the finite elements method, including 3D, and is sufficiently approved in solving similar problems [12].

The stress-strain behavior characteristics in the bottomhole area of the shaft were determined in three experimental sites described above. The general view and a fragment of 3D section of test site No. 1 are shown in Fig. $\mathbf{5}$.

The model has a cylindrical shape. To eliminate the influence of the boundary conditions on the calculation, the height and diameter of the model are taken to be more than $10 \mathrm{D}$, where $\mathrm{D}$ is the diameter of the shaft. Furthermore, in order to
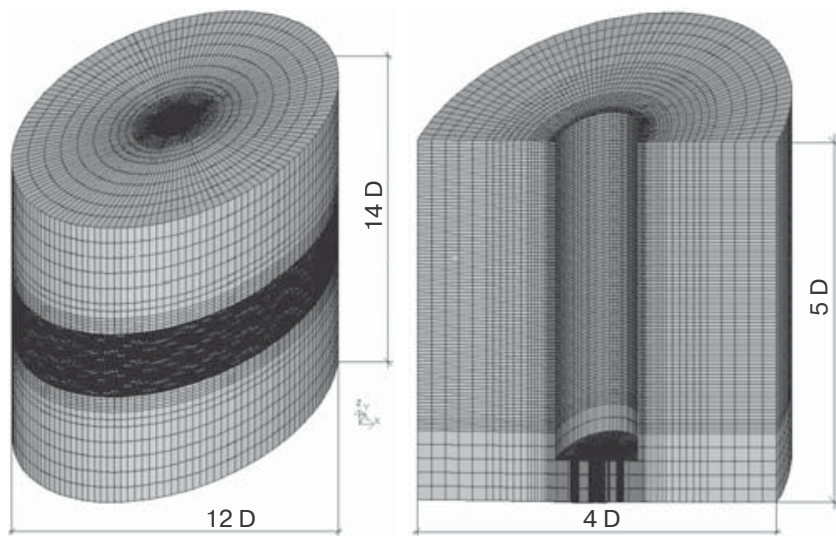

Fig. 5. Finite element model of shaft bottomhole area:

(a) general view; (b) fragment of the sectional view.

account for inaccurate setting of the model loads, the adjusting factor a determined from the measurement data is introduced.

The spatial isoparametric eight-node finite elements were used to model shotcrete and concrete lining, as well as rock mass. These elements allow us to determine the stress-strain behavior of continuum bodies and massive spatial structures in physically nonlinear elasticity (it is assumed that the material has isotropic properties at the initial stage).

The bolting was modeled with the help of rod finite elements.

The lining support was represented by three-dimensional elements with a face length of $0.1 \mathrm{~m}$. The finite-element network of the rock mass was constructed using the principle of combining dense and enlarged networks. The size of the finite elements in the section of the model with the 2D diameter was gradually increased from 0.1 to $1.0 \mathrm{~m}$ in the radial direction. The outer ring of the model, and the lower and upper layers were represented in the form of an enlarged finite element network with a face size of 1.0-5.0 m.

In order to take into account non-linear deformation of rock mass, reinforced rocks and lining, the finite elements were given properties of physical nonlinearity and obeyed the accepted law of deformation. We used the, the exponential stress-strain curves from the lab-scale tests of rocks (Fig. 6).

The calculation by the step-iteration method included some assumptions described below. 

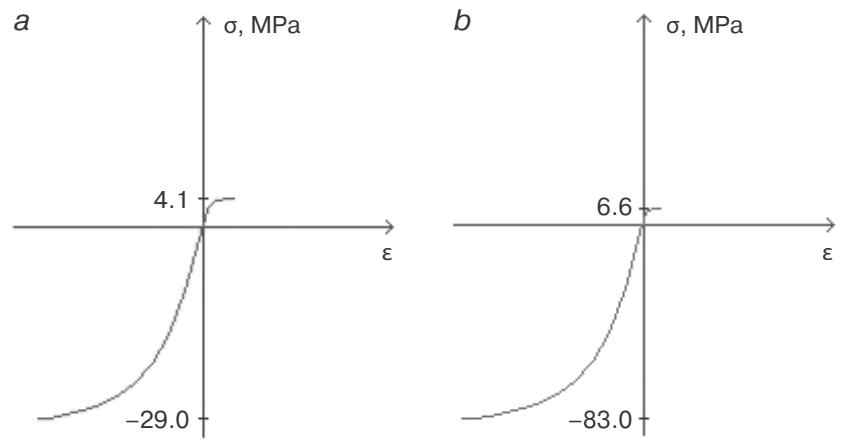

Fig. 6. Exponential $\sigma(\varepsilon)$ curves for rock mass modeling:

(a) siltstone; (b) sandstone (compressive stresses are assumed to be negative)

The general stress - strain behavior is characterized by three components of the displacement vector $-u_{x}, u_{y}, u_{z}$, six components of the strain tensor $-\varepsilon_{x}, \varepsilon_{y}, \varepsilon_{z^{\prime}}, \varepsilon_{x y}, \varepsilon_{y z}, \varepsilon_{z x}$ and six components of the stress tensor $-\sigma_{x}, \sigma_{y}, \sigma_{z}, \sigma_{x y}, \sigma_{y z}, \sigma_{z x}$.

Denoting by $u_{n}, \vec{u}_{t}, \sigma_{n}, \vec{\sigma}_{t}$ respectively, the normal and shear components of the displacement and stress vectors at the outer boundaries of the model and at the contact surfaces, we can determine the boundary conditions.

At the upper boundary conditions of the model take into account the weight of overlying rocks:

$$
\sigma_{n}=-a \gamma H ; \vec{\sigma}_{t}=0 \text {, }
$$
where $a$ is the adjusting factor introduced to take into account the difference of the real rock mass stress field from the calculated stresses and to avoid initial displacements in rocks. This factor is determined from the measurements of the shaft rock wall displacement in the bottomhole area: $a=0.93$; $\gamma$ is the average bulk density of overlying rocks; $H$ is the distance from ground surface to the test site (the upper boundary of the model).
The following conditions are fulfilled on the lateral cylindrical surface of the model:

$u_{n}=0 ; \vec{\sigma}_{t}=0$.

Introducing the assumption that the horizontal sections of rock mass remain flat after the shaft sinking, the same boundary conditions are set at the lower face of the model on the basis of symmetry considerations:

$$
u_{n}=0 ; \vec{\sigma}_{t}=0 \text {. }
$$

At interfaces of rock layers, as well as at the contacts between shotcrete, and concrete lining and rock mass, the boundary conditions of complete adhesion are set:

$$
\vec{u}^{\prime}=\vec{u}^{\prime \prime} ; \vec{\sigma}_{t}^{\prime} \neq \vec{\sigma}^{\prime \prime} \text {. }
$$

where the dash denotes the normal components of the displacement vectors related to the $m$-th layer, and the two dashes are the components related to the $(m+1)$-th layer or the shaft lining.

\section{Results}

Figure 7 presents the graphical distributions of the measured tensile forces along the rock bolts. The curves are plotted from the statistic processing of the test data in Excel. The dashed lines show the numerical modeling values of the forces (computer simulations were performed for rock bolts with fulllength grouting).

The quantitative analysis of the forces in the rock bolts shows that the rock bolts in the first experimental sites experience the least stress. When the bolt is grouted to the full length, the average values of the maximum forces are about $37 \mathrm{kN}$; at the grouting length $I=1.4 \mathrm{~m}$, the maximum forces reach $52.5 \mathrm{kN}$; at $I=1.0 \mathrm{~m}, 67 \mathrm{kN}$.

The rock bolts installed in the experimental sites Nos. 2 and 3 are subjected to more intensive loading. This can be explained by the greater depth of the shaft in the former case and by the high deformability of the environment in the latter case.
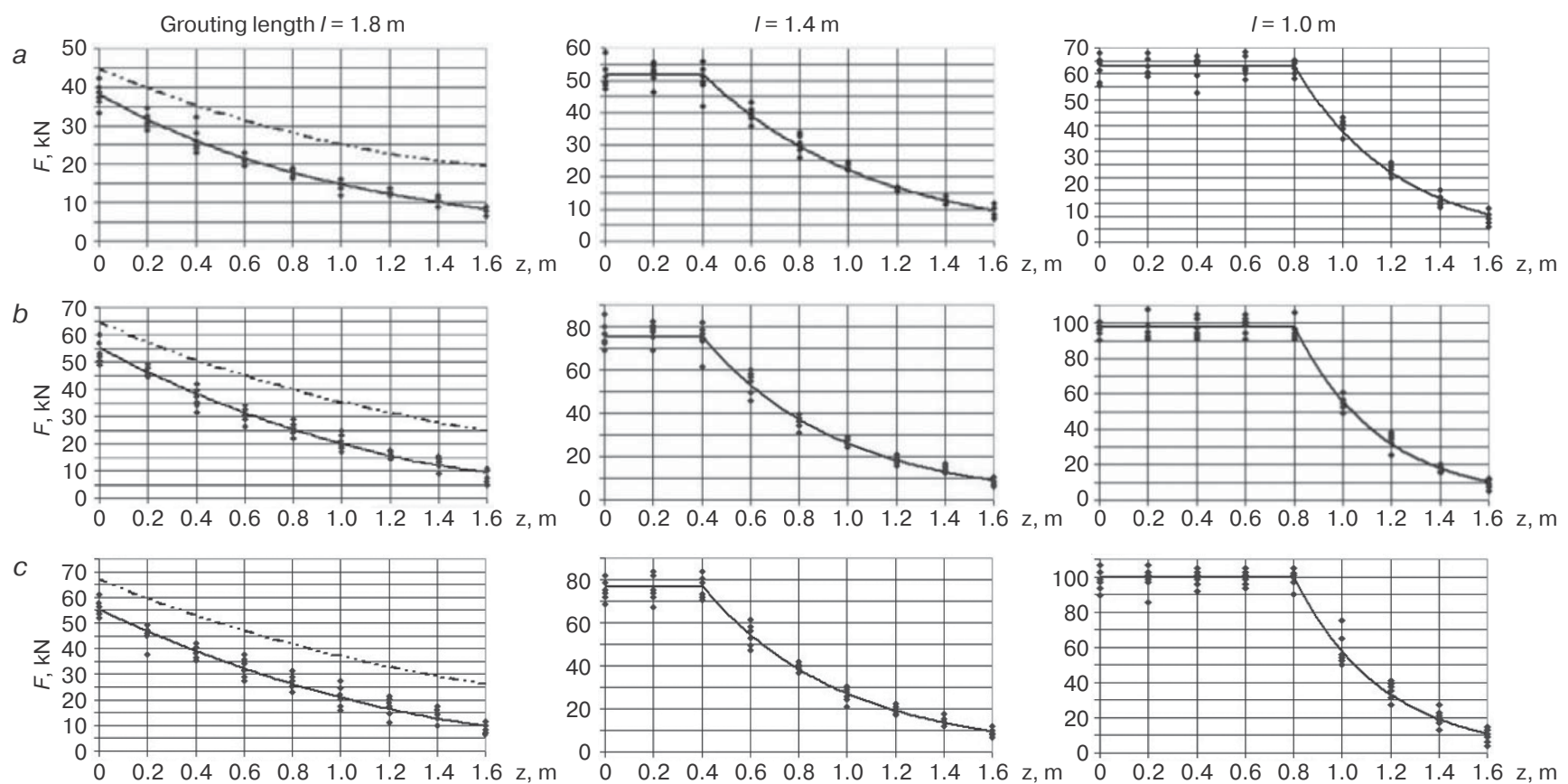

Fig. 7. Distribution of tensile forces along rock bolts in three experimental sites:

(a) first site; (b) second section; (c) third site 
Table 3. Calculation results for support components in three experimental sites

\begin{tabular}{|c|c|c|c|}
\hline $\begin{array}{l}\text { Shaft support } \\
\text { components }\end{array}$ & $\begin{array}{c}\text { Unit of } \\
\text { measurement }\end{array}$ & $\begin{array}{c}\text { Maximum } \\
\text { stresses (forces) }\end{array}$ & $\begin{array}{l}\text { Safety coefficient with regard } \\
\text { to decreasing coefficients }\end{array}$ \\
\hline \multicolumn{4}{|c|}{ Site No. 1} \\
\hline Bolting & $\mathrm{kN}$ & 45.01 & 2.8 \\
\hline $\begin{array}{l}\text { Shotcrete temporary } \\
\text { lining }\end{array}$ & $\mathrm{MPa}$ & 1.62 & 3.79 \\
\hline $\begin{array}{l}\text { Monolithic concrete } \\
\text { permanent lining }\end{array}$ & $\mathrm{MPa}$ & 0.97 & 6.33 \\
\hline \multicolumn{4}{|c|}{ Site No. 2} \\
\hline Bolting & $\mathrm{kN}$ & 65.04 & 1.94 \\
\hline $\begin{array}{l}\text { Shotcrete temporary } \\
\text { lining }\end{array}$ & $\mathrm{MPa}$ & 2.37 & 2.59 \\
\hline $\begin{array}{l}\text { Monolithic concrete } \\
\text { permanent lining }\end{array}$ & $\mathrm{MPa}$ & 1.47 & 4.18 \\
\hline \multicolumn{4}{|c|}{ Site No. 3} \\
\hline Bolting & $\mathrm{kN}$ & \begin{tabular}{|r|}
67.33 \\
\end{tabular} & 1.87 \\
\hline $\begin{array}{l}\text { Shotcrete temporary } \\
\text { lining }\end{array}$ & $\mathrm{MPa}$ & 2.89 & 2.12 \\
\hline $\begin{array}{l}\text { Monolithic concrete } \\
\text { permanent lining }\end{array}$ & $\mathrm{MPa}$ & 1.54 & 3.99 \\
\hline
\end{tabular}

The average values of the measured maximum tensile forces in the rock bolts are:

- Site No. 2: $F_{\max }=55 \mathrm{kN}$ at $I=1.8 \mathrm{~m} ; F_{\max }=75.5 \mathrm{kN}$ at $I=1.4 \mathrm{~m} ; F_{\max }=99 \mathrm{kN}$ at $I=1.0 \mathrm{~m}$;

- Site No. 3: $F_{\max }=55.5 \mathrm{kN}$ at $I=1.8 \mathrm{~m} ; F_{\max }=77.5 \mathrm{kN}$ at $I=1.4 \mathrm{~m} ; F_{\max }=100.5 \mathrm{kN}$ at $I=1.0 \mathrm{~m}$.

In all experimental sites, the minimum measured forces in the rock bolts take place when the bolt grouted to the full length. At $I=1.4 \mathrm{~m}$ and $I=1.0 \mathrm{~m}$, the maximum force is greater by 1.31 and 1.72 times, respectively.

The comparison of the experimental and calculated data points at the identical qualitative distribution of the tensile forces along the rock bolts with the full-length grouting in all experimental sites. The deviation of the maximum forces never exceeds $19 \%$. The higher calculated values can be explained by the fact that numerical modeling neglects some structural yield of the rock bolts. This provides an additional margin for the load-bearing capacity of the bolting and enables better stress relaxation of rock mass before installation of the permanent lining. The satisfactory convergence of the quantitative and qualitative results in three experimental sites demonstrates the correctness of the studies and the possibility of evaluating the other characteristics of the stress-strain behavior by numerical methods.

The numerical modeling results obtained in three experimental sites are summarized in Table $\mathbf{3}$.

According to Table 3 , the permanent lining of shallow shafts has a sufficient safety coefficient. At the same time, for sections of shafts at depths greater than $700 \mathrm{~m}$ in similar engineering and geological conditions, the use of higher class concrete B25 with the estimated compressive strength $R_{b}=14.5 \mathrm{MPa}$ is recommended.

\section{Discussion}

The proposed approach to studying operation of temporary and permanent lining in shafts during sinking should be considered quite promising. The comparative analysis of the stressed-strain behavior of the lining in the bottomhole area of the shaft, performed by the methods of real-time monitoring and numerical simulation, verifies the correctness of the numerical model, on the one hand, and to simplify monitoring during the shaft construction period, on the other hand. In case of identifying hazardous stresses in the temporary lining, it is possible to adjust promptly the main lining parameters before installation. This creates prerequisites for improving safety of construction and operation of deep vertical shafts.

At the same time, one can note the rather high laboriousness of the numerical modeling of the bottomhole area with the use of spatial models and stepwise iterative procedures. The high qualification of the researcher, the modeling of material deformation the non-linearity, structural heterogeneity and fracturing of the massif, the sequence of entry of the lining elements into work, adequate to real conditions, are necessary. For the most accurate assessment, it is also necessary to take into account the structural compliance of the anchors and the variable rigidity of the shotcrete and concrete lining in the early stages of concrete hardening.

For the situations where excessive deformations can occur in the shat, it is recommended the use of bolts or anchors that can accommodate large deformations and keep almost constant resistance during the process of elongation [13-14].

\section{Conclusions}

Based on the research result, the following conclusions can be formulated:

1. With the increasing depth of shafts depth and higher hazard of sinking, there is a necessity for the most accurate assessment of the actual stress-strain behavior of the shaft lining. As an effective approach to the solution of this problem, it is proposed to implement the real-time monitoring during sinking while lining installation, and the numerical modeling of the bottomhole area of the shaft.

2. The proposed method of monitoring one of the parameters of the lining-rock mass stress-strain behavior in combination with the computer modeling of the lining-rock mass system makes it possible to simplify monitoring and to reduce the time and material costs of the process. As a result of this research, it has been proved that such parameter can be the tensile forces in the rock bolts of the temporary shaft support.

3. The comparison of experimental and numerical simulation data reveals the similar qualitative distribution of the tensile forces along the rock bolts. The deviation of the force values in three experimental sites never exceeds 19\%. The higher calculated values can be explained by the fact that numerical modeling neglects structural yielding of the rock bolts. Thus, the correctness of the numerical models has been confirmed.

4. The proposed spatial numerical model of the bottomhole area of the shaft with the use of the stepwise iterative procedures allows determining the maximum forces and stresses in the shaft support and the load-bearing capacity of the structures, as well as enables reasoned decision-making 
on the shaft support and reinforcement at depths greater than $700 \mathrm{zm}$.

References

1. Pleshko M. S., Stradanchenko S. G., Maslennikov S. A., Pashkov $O$. V. Study of technical solutions to strengthen the lining of the barrel in the zone of influence of construction near-wellbore production. ARPN Journal of Engineering and Applied Sciences. 2015. Vol. 10(1). pp. 14-19.

2. Walton G., Kim E., Sinha S., Sturgis G., Berberick D. Investigation of shaft stability and anisotropic deformation in a deep shaft in Idaho, United States. International Journal of Rock Mechanics and Mining Sciences. 2018. Vol. 105. pp. 160-171.

3. Kaledin O. S. Innovative technologies for the construction of superdeep mine shafts. Mining Journal. 2014. No. 4. pp. 77-81.

4. Tarasov V. V., Koshev G. Ya., Zagvozdkin I. V. Solution of security problems in the construction of vertical shafts at potash deposits. Industry labour safety. 2015. Vol. 8. pp. 64-67.

5. Tarasov V. V., Pestrikova V. S. Overview of emergencies that occurred at the Verkhnekamsk potassium salt deposit during the mining of shafts. GIAB. 2015. No. 5. pp. 23-29.

6. Xiaowei Feng, Nong Zhang, Fei Xue, Zhengzheng Xie. Practices, experience, and lessons learned based on field observations of support failures in some Chinese coal mines. International Journal of Rock Mechanics and Mining Sciences. 2019. Vol. 123. 104097. DOI: 10.1016/j.jirmms.2019.104097

7. Corkum A. G., Damjanac B., Lam T. Variation of horizontal in situ stress with depth for long-term performance evaluation of the Deep Geological Repository project access shaft. Interna- tional Journal of Rock Mechanics and Mining Sciences. 2018. Vol. 107. pp. 75-85.

8. Strickland B., Board M., Sturgis G., Berberick D. Elliptical shaft excavation in response to depth induced ground pressure. SME Annual Conference and Expo: The Future for Mining in a Data-Driven World. 2016. pp. 407-412.

9. Kharisov T. F. Mine shaft rock walls convergence investigations in the conditions of the out-of-limit state of the borehole massif. Izvestiya vuzov. Gornyi zhurnal. 2017. No. 5, pp. 46-51.

10. Sousa L. R., Sousa R. L., Vargas Jr. E., Velloso R., Karam K. Risk assessment on $\mathrm{CO}_{2}$ injection processes and storage. Rock Mechanics and Rock Engineering. 2017. Vol. 3(12). pp. 359-397.

11. Pleshko M. S., Silchenko Yu. A., Pankratenko A. N., Nasonov A. A Improvement of the analysis and calculation methods of mine shaft design. GIAB. 2019. No. 12. pp. 55-66.

12. Pleshko M. S., Pashkova O. V., Nasonov A. A. Analysis of geometrical nonuniformityf lining in operating shafts and its influence on shaft stability. Gornyi Zhirnal. 2015. No. 3. pp. 33-37. DOI: $10.17580 /$ gzh.2015.03.05

13. He M., Li. C., Gong W., Sousa L. R., Li S. Dynamic tests for a constant-resistance-large-deformation bolt using a modified SHTB system. Journal of Tunneling and Underground Space Technology. 2017. Vol. 64. pp. 103-116.

14. Shuxue D., Hongwen J., Kunfu C., Guo'an X. Bo, M. Stress evolution and support mechanism of a bolt anchored in a rock mass with a weak interlayer. International Journal of Mining Science and Technology. 2017. Vol. 27. pp. 573-580.

\section{GEOMECHANICAL SUBSTANTIATION OF THE NORTHEASTERN PIT WALL STABILITY IN KURZHUNKUL MINE}

\section{Introduction}

Structural heterogeneity, extensional tectonics, jointing and broken bedding are the critical factors of higher concern in mineral mining safety. All other geological and geophysical processes are controllable and are governed by the extensional tectonics $[1,2]$.

From the engineering geology data, the Kurzhunkul open pit mine field is intersected by premineral NE-striking faults with NW dips at $80-85^{\circ}$ and by NW-striking faults with SW dips at the same angles, and represents a small- and medium-size blocky rock mass. Tectonic faults are oriented ether north-southward, or west-eastward, north-eastward and north-westward, and represent either normal faults, or shifty faults and overthrusts, which condition the broken blocky structure of the region.
Kurzhunkul magnetite deposit is located in the Kostanai Region of Kazakhstan and is an open pit mining project of Sokolovsko-Sarbay Mining and Production Association (SSGPO) since 1983. The current depth of the open pit is $240 \mathrm{~m}$ (Level-28m). It is expected that Kurzhunkul pit reaches the depth of $290 \mathrm{~m}$. The deformation determinant in Kurzhunkul mine is its geological structure represented by complex faulting. Special care and attention should be paid to the northeastern pit wall which is a zone of large and closely spaced tectonic faults essentially extended along the strike and dip of the deposit, and depthward the pit. Unfavorable bedding conditions in combination with weak physical and mechanical properties of fracture fillers can induce movement of rock blocks during extraction of mineral reserves from the weak zone of the northeastern pit wall. This study offers the geomechanical substantiation of stability of NE Kurzhunkul pit wall which is most heavily intersected by tectonic faults and has low strength characteristics.

Keywords: open pit mine, tectonic faults, stability, physical and mechanical properties, stability factor.

DOI: $10.17580 / \mathrm{em} .2021 .01 .06$ 